\title{
Effects of Corticosteroids on Distribution of Histamine in the Blood of Asthmatic Children
}

\author{
J. F. PORTER, J. A. YOUNG, and R. G. MITCHELL \\ From the Department of Child Health, University of Aberdeen, Foresterhill, Aberdeen AB9 2ZD, Scotland
}

Porter, J. F., Young, J. A., and Mitchell, R. G. (1970). Archives of Disease in Childhood, 45, 54. Effects of corticosteroids on distribution of histamine in the blood of asthmatic children. Blood and plasma histamine levels, together with circulating basophil and eosinophil counts, were estimated in a group of asthmatic children.

Short-term studies were carried out on 7 patients, each of whom was given a single dose of corticosteroid, and the effects of the hormone were monitored for periods of up to two hours. Usually a fall occurred in the whole blood histamine level, basophil count, and eosinophil count, but no change occurred in the plasma histamine level, which remained very low throughout.

In 3 cases, follow-up studies showed that in 2 cases out of 3, whole blood histamine levels were lower during treatment with corticosteroids, than when steroids were not being given.

Asthmatic patients tend to have higher whole blood histamine levels than healthy subjects (Haworth and McDonald, 1937; DeGara, 1951), and these increased levels are often associated with raised basophil and eosinophil leucocyte counts (Porter and Mitchell, 1970).

On administration of corticosteroid hormones, the whole blood histamine level generally falls (Code and Mitchell, 1957; Gudowski and Dieckhoff, 1967), and patients on long-term corticosteroid therapy tend to have lowered whole blood histamine levels, basophil counts, and eosinophil counts (Porter and Mitchell, 1970).

Plasma histamine levels in healthy children have been reported as very low (Mitchell and Cass, 1959), and similarly low levels have been found in asthmatic children in both active and quiescent states (Porter and Mitchell, 1970). Noah and Brand (1957), using a relatively insensitive assay technique on a small group of patients, could not detect histamine in the plasma after administration of corticosteroids. These findings have been substantiated to some degree by Porter and Mitchell, who used the very sensitive techniques of Adam, Hardwick, and Spencer (1954, 1957) in a larger group of subjects, and found no measurable amounts of histamine (less than $1 \mathrm{ng} . / \mathrm{ml}$.) in the

Received 28 July 1969. plasma of asthmatic children on long-term corticosteroid therapy.

The present investigation was undertaken to measure changes in the whole blood and plasma histamine levels, and in circulating basophil and eosinophil leucocyte counts on administration and withdrawal of corticosteroid hormones. Both short-term and long-term follow-up studies were undertaken.

\section{Materials and Methods}

Ten asthmatic children were studied; some had atopic eczema, and the precipitating factors of the acute attacks included reaction to extraneous allergens, infection, and psychological upset. The opportunity offered by a therapeutic trial of different methods of administering corticosteroids in asthma was taken to investigate the effects of therapy on the metabolism of histamine.

The 10 children formed two groups. The first contained 7 children who were suffering from acute attacks; they were given single large doses of corticosteroid (usually prednisolone equivalent to $100-200 \mathrm{mg}$. hydrocortisone); the effects of the hormone were then followed for up to 2 hours. The second group consisted of 3 patients who were examined periodically for several weeks; all 3 were taking corticosteroids at some stage of the study.

Plasma and whole blood histamine levels were estimated in samples of blood from the antecubital veins 
using slightly modified versions of the methods of Adam et al. (1957) and Adam (1961). This entailed an initial two-stage centrifugation at $4^{\circ} \mathrm{C}$. to separate the plasma from the cells. Plasma and whole blood specimens were then extracted with trichloroacetic acid, centrifuged to remove the proteins, and further purified on composite cationic resin columns. The eluates, after heating with $6 \mathrm{M} \mathrm{HCl}$ and drying, were reconstituted and assayed on the superfused guinea-pig ileum preparation as described by Adam et al. (1954).

Basophil and eosinophil leucocytes were counted in both venous and capillary blood using Mitchell's modification (1955) of the method of Moore and James (1953). This involved the use of a diluting fluid containing toluidine blue which metachromatically stained the basophils and eosinophils.

\section{Results}

Short-term studies. The effects of single doses of corticosteroids administered to 7 patients with severe acute asthma were followed over short periods. In some cases, it was possible to monitor the circulating basophils and eosinophils approximately every 30 minutes by sampling from the capillaries (finger-prick). It was not practicable, however, to withdraw venous blood for plasma and whole blood estimations more than twice during a test, as this required relatively large volumes of blood and necessitated venepuncture. Results are shown in Fig. 1, 2, and 3.
Generally, there was a fall in the whole blood histamine level after administration of the hormone. This was seen in all the patients on whom these estimations were performed, except in one (Case 5) who showed a slight rise in the whole blood histamine 20 minutes after a dose of hydrocortisone (100 mg.). This rise in whole blood histamine coincided with a rise in the circulating basophil count.

In the cases where serial basophil counts were performed, falls in cell numbers were seen after administration of corticosteroids. In 3 cases, parallel basophil and eosinophil counts were carried out, and in 2 of these (Cases 1 and 3) the eosinophil cell count began to fall after the basophils; there was also an initial rise in the eosinophil count before the fall. In Case 5, there was an initial rise in the basophil count after 20 minutes, which was then followed by a fall in the count.

In the 4 cases in which cell counts were carried out only on 2 occasions (a 'basal' and a 'poststeroid' estimation), the fall in histamine levels was accompanied by a fall in both basophil and eosinophil counts in 2 cases, in basophils in 1 case (Case 6 ), and in eosinophils only in the fourth case (Case 7).

The plasma histamine levels in all 7 patients were minimal for both the 'basal' and 'poststeroid' specimens (reported as less than $1 \mathrm{ng} . / \mathrm{ml}$.).
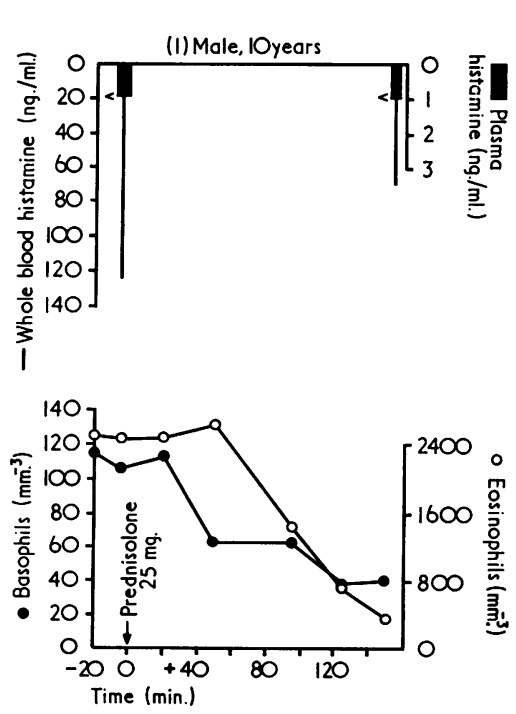
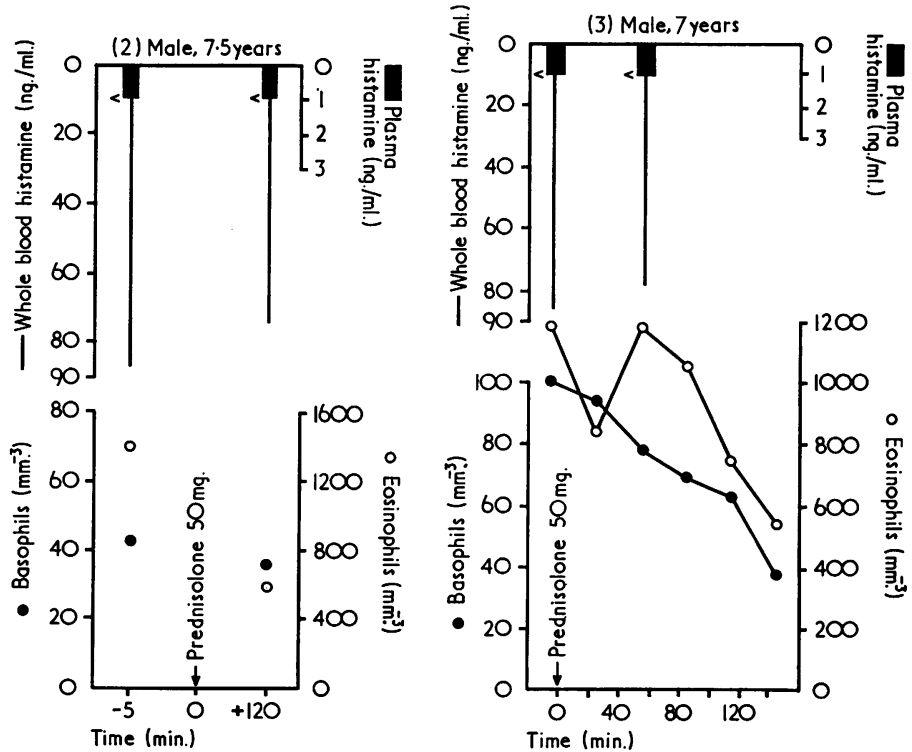

FIG. 1.-The effects of short-term corticosteroid therapy on the numbers of basophil and eosinophil leucocytes, and whole blood and plasma histamine levels in Cases 1, 2, and 3. 

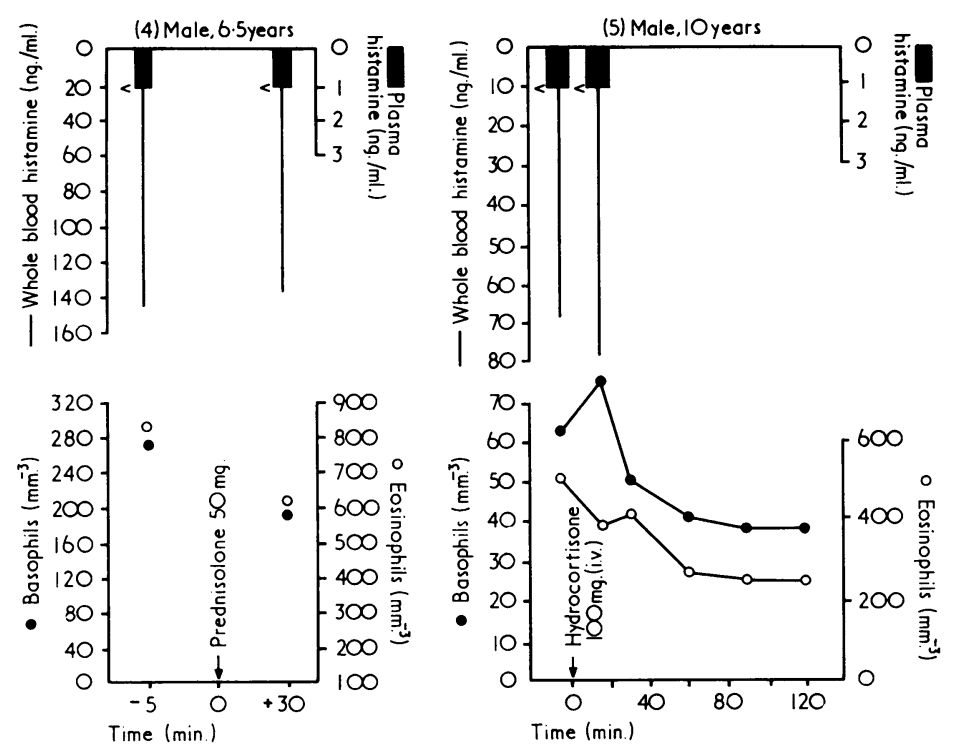

FIG. 2.-The effects of short-term corticosteroid therapy on Cases 4 and 5.

Follow-up studies. These were carried out on 3 boys and the results are shown in the Table. In 2 of these children, the whole blood histamine levels were lower during steroid treatment than when they were not receiving hormones, and a similar reduction in the basophil and eosinophil counts was recorded in Case 9. Case 10, however. showed no fall in histamine levels or basofhit counts during steroid treatment. In none of these 3 cases was histamine detected in the plasing specimens, this very low level being again reportee as less than $1 \mathrm{ng} . / \mathrm{ml}$.
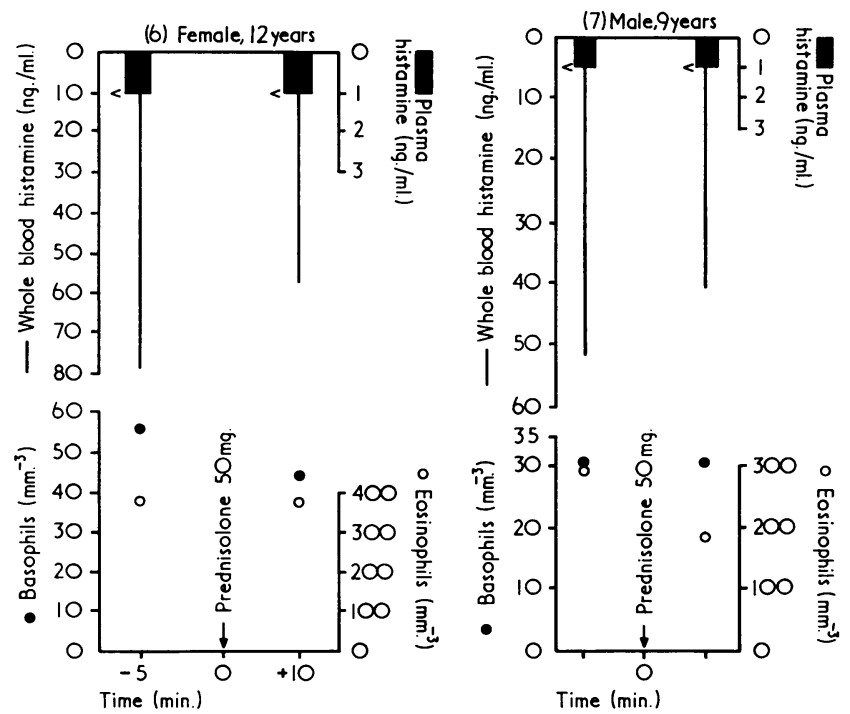

FIG. 3.-The effects of short-term corticosteroid therapy on Cases 6 and 7. 
TABLE

Follow-up Studies on 3 Children with Chronic Asthma

\begin{tabular}{|c|c|c|c|c|c|c|c|}
\hline Case No. & $\begin{array}{c}\text { Age at First } \\
\text { Examination } \\
\quad(y r)\end{array}$ & $\begin{array}{c}\text { Date of } \\
\text { Examination }\end{array}$ & Steroids & $\begin{array}{l}\text { Whole Blood } \\
\text { Histamine } \\
\text { (ng./ml.) }\end{array}$ & $\begin{array}{l}\text { Plasma Hista- } \\
\text { mine (ng./ml.) }\end{array}$ & $\begin{array}{c}\text { Basophils } \\
\text { (per cu. mm.) }\end{array}$ & $\begin{array}{l}\text { Eosinophils } \\
\text { (per cu. mm.) }\end{array}$ \\
\hline 8 & $5 \frac{1}{2}$ & $\begin{array}{l}28.2 .68 \\
26.8 .68\end{array}$ & + & $\begin{array}{r}17 \\
133\end{array}$ & $\begin{array}{l}<1 \\
-\end{array}$ & $\begin{array}{l}56 \\
-\end{array}$ & $\begin{array}{l}67 \\
-\end{array}$ \\
\hline 9 & $6 \frac{1}{2}$ & $\begin{array}{l}18.8 .67 \\
18.4 .68\end{array}$ & $\overline{+}$ & $\begin{array}{r}155 \\
39\end{array}$ & $\begin{array}{l}<1 \\
<1\end{array}$ & $\begin{array}{r}227 \\
53\end{array}$ & $\begin{array}{r}491 \\
97\end{array}$ \\
\hline 10 & 7 & $\begin{array}{c}18.4 .68 \\
5.6 .68 \\
11.11 .68 \\
3.2 .69\end{array}$ & $\begin{array}{l}- \\
- \\
+ \\
+\end{array}$ & $\begin{array}{l}87 \\
66 \\
75 \\
75\end{array}$ & $\begin{array}{l}<1 \\
<1 \\
<1 \\
<1\end{array}$ & $\begin{array}{r}100 \\
60 \\
47 \\
63\end{array}$ & $\begin{array}{r}1189 \\
905 \\
401 \\
1062\end{array}$ \\
\hline
\end{tabular}

\section{Discussion}

In the group of 7 asthmatic children where the effects of single-dose corticosteroid therapy were studied, it was found that administration of the hormone was followed by a prompt fall in the basophil and eosinophil counts. This fall was often quite pronounced and after 2 hours the counts were often down to normal values. These lowered cell counts were not considered to be due to haemodilution, as parallel total leucocyte counts which were performed in 5 cases showed no significant changes after the hormone. It was considered that the fall in basophil counts after administration of the hormone might be due to degranulation and that, if such were the case, there might be a detectable release of histamine into the plasma. Such an effect would explain the modest but significant increases in urinary excretion of free histamine after administration of corticosteroids reported by Mitchell and Code (1954). Therefore blood specimens for plasma and whole blood histamine were withdrawn at varying intervals after administration of the hormone. On no occasion, however, was a rise in plasma histamine detected, though a fall in the whole blood histamine concomitant with a fall in the basophil count was usually seen.

This could mean that the basophils are not degranulated but removed to other sites or, alternatively, that histamine is released by the basophils and taken up by the eosinophils. The latter hypothesis could explain the slight rise in eosinophil counts sometimes seen after administration of corticosteroids, and would be in accord with the theory that eosinophils take up and inactivate histamine (Archer, 1960).

Recent work by Kovács and Suffiad (1968) has shown that massive doses of corticosteroids in guinea-pigs can cause a release of histamine into the plasma. These workers concluded that this release was due to the hyperglycaemic effects of the hormone. It would be interesting therefore to study the histamine levels of plasma specimens from patients with hyperglycaemia.

Clinical improvement usually followed soon after administration of the single corticosteroid dose, sometimes so rapidly that the effect seemed to be psychological rather than pharmacological. Thus in Case 2 the effects were instantaneous and in Cases 6 and 7 improvement was seen after 2 or 3 minutes.

In the follow-up studies, 2 out of the 3 cases had histamine levels and cell counts decidedly lower during corticosteroid therapy than in periods without hormone treatment. This was in general agreement with the findings in another group of asthmatic children on long-term steroid therapy (Porter and Mitchell, 1970).

The authors wish to thank the Asthma Research Council for financial support, Miss Sandra Smith for technical assistance, and Dr. G. Russell for the provision of specimens from the follow-up patients.

\section{REFERENCES}

Adam, H. M. (1961). Histamine in the central nervous system and hypophysis of the dog. In Regional Neurochemistry, p. 293. Ed. by S. S. Kety, and J. Elkes, Pergamon, Oxford.

- Hardwick, D. C., and Spencer, K. E. V. (1954). Assay of histamine on the isolated guinea-pig intestine by the method of superfusion. British fournal of Pharmacology and Chemotherapy, 9, 360 .

, - , and - (1957). A method of estimating histamine in plasma. ibid., 12, 397.

Archer, R. K. (1960). Eosinophil leucocyte-attracting effect of histamine in skin. Nature (London), 187, 155.

Code, C. F., and Mitchell, R. G. (1957). Histamine, eosinophils and basophils in the blood. fournal of Physiology, 136, 449.

DeGara, P. F. (1951). Chemical determination of histamine in blood in health and disease. Fournal of Allergy, 22, 429.

Gudowski, G., and Dieckhoff, J. (1967). Basophile Leukozyten und Histamin im Blut bei allergischen Reaktionskrankheiten im Kindesalter. Allergie und Asthma, 13, 1. 
Haworth, E., and McDonald, A. D. (1937). On histamine in cotton dust and in the blood of cotton workers. Fournal of Hygiene (London), 37, 234.

Kovács, E. M., and Suffiad, K. (1968). Histamine release by cortisone induced hyperglycaemia. British fournal of Pharmacology and Chemotherapy, 32, 262.

Mitchell, R. G. (1955). Circulating basophilic leucocyte counts in the newborn. Archives of Disease in Childhood, 30, 130.

- and Cass R. (1959). Histamine and 5-hydroxytryptamine in the blood of infants and children. Fournal of Clinical Investigation, 38, 595.

- - and Code, C. F. (1954). Urinary excretion of histamine after administration of cortisone. Fournal of Clinical Endocrinology and Metabolism, 14, 707.
Moore, J. E., and James, G. W. (1953). A simple direct method f absolute basophil leucocyte count. Proceedings of the Socidy for Experimental Biology and Medicine, 82, 601.

Noah, J. W., and Brand, A. (1957). The effect of corticoster. administration upon blood histamine content. Fournal of Allergy, 28, 405.

Porter, J. F., and Mitchell, R. G. (1970). The distribution of histamine in the blood of healthy and asthmatic childr. Clinical Science. In the press.

Correspondence to Professor R. G. Mitchell, Depat? ment of Child Health, University of Aberdeen, Foresteehill, Aberdeen AB9 2ZD. 